\title{
Thermal and mechanical transient behaviour of steel doors installed in non-load bearing partition walls assemblies during exposure to the standard fire test
}

Ayman Y. Nassif a, Isamu Yoshitake ${ }^{\mathrm{b}}$, Vanissorn Vimonsatit ${ }^{\mathrm{c}}$

a School of Civil Engineering and Surveying, University of Portsmouth, Portsmouth PO1 3AH, United Kingdom. Tel: +44(0)2392842392, Fax: +44(0)2392842521 E-mail address:

ayman.nassif@port.ac.uk

b Department of Civil and Environmental Engineering, Yamaguchi University, Tokiwadai 2-16-1, Ube, Yamaguchi 755-8611, Japan.

Email: yositake@yamaguchi-u.ac.jp

c School of Civil and Mechanical Engineering, Faculty of Science and Engineering, Curtin University, Bentley Campus, Perth, Australia.

Email v.vimonsatit@curtin.edu.au 


\section{ABSTRACT}

In this paper, the authors present experimental results and observations of four full-scale standard fire tests on single-leaf steel doors and steel frames installed in 3x3 m non-load bearing partition walls. Three full-scale fire tests were performed on steel doors installed in lightweight partition walls constructed using steel C-sections studs with gypsum boards fixed on both sides. Two lightweight walls incorporated Rockwool cavity insulation while the third lightweight wall was constructed without cavity insulation. The fourth fire test involved a steel door installed in a masonry partition wall.

While the steel door-leaf and door-frames were identical in all four full-scale tests, only the steel door installed in the masonry wall achieved the desired fire resistance rating of 30 minutes. The integrity criterion for fire resistance was determined for the scenario when the door opened away from the furnace. The duration of fire resistance according to the integrity criterion was found to be 38, 25 and 19 minutes for the same door when installed in masonry wall, uninsulated lightweight wall and insulated lightweight wall respectively.

For the thermal insulation criterion of fire resistance, the scenario of the door opening into the fire was found to be the most onerous.

KEY WORDS: Fire Testing, Partition walls, Steel Doors, Fire resistance 


\section{INTRODUCTION}

Fire resistance failure leads to devastating events with possible loss of life and assets. The global research efforts in fire engineering gained more momentum after the attacks on the World Trade Centre in 2001 which caused fire engineering failure of the towers [1].

Fire resistance rating of building components and assemblies is based on a standard fire exposure according to the code of practice adopted in each country. The minimum duration of exposure to the standard fire until a fire failure criterion is reached determines the fire resistance rating of the component or the assembly. The national and international codes of practice provide clear definition of the fire resistance criteria, namely: integrity, insulation and load-bearing. Lightweight partition wall systems constructed using vertical steel studs and plaster boards are widely used in buildings due to cost effectiveness and speed of construction. Such wall systems can be constructed incorporating steel doors or without any opening. Lightweight wall systems are usually designed as non-load bearing elements with the fire resistance as a major design requirement.

This paper reports the second phase of a larger research project investigating the behaviour of such wall-door assemblies. The project was supported by multinational manufacturers of plasterboards and steel doors systems. The first phase, which was previously reported by Nassif et al. [2], was concerned with the fire behaviour of partition wall systems without inclusion of a door. The behaviour of steel-studs gypsum-faced walls during exposure to fires was investigated by a number of researchers [2-10]. Such research efforts were concerned with the behaviour of such walls without the inclusion of doors in the tested walls. 
Nassif et al. [2] presented experimental data obtained from full-scale fire testing on gypsum-faced steel-studs partition walls without the inclusion of doors. The walls were constructed using steel studs with gypsum boards fixed on both sides. The cavity was either filled with Rockwool insulation or left empty. The transient thermal profiles together with the displacements during the fire tests were documented. The data was used to develop, calibrate and verify a numerical procedure to predict the thermal and mechanical behaviour of such walls during fire exposure. Previously, a number of studies related to the thermal response of such partition walls systems were conducted. However, the mechanical response during fires had not been sufficiently investigated for a typical wall height of $3 \times 3 \mathrm{~m}$. A review of the literature regarding the behaviour of steel-studs gypsum-faced walls was outlined by Nassif et al. [2]. A brief review of aspects of research related to such walls is included here for the readers’ convenience.

Alfawakhiri et al. [3] provided a detailed review of the fire resistance aspects of load-bearing steelstuds walls protected by gypsum boards. The need to adopt a performance based fire engineering design was highlighted. The prescriptive design based on costly time consuming certification obtained by full-scale standard fire testing was highlighted as limiting. The criticism related to the narrow application of the standard fire testing was explored. The one-dimensional thermal model reported by Sultan [4] at the Institute for Research in Construction (IRC), National Research Council of Canada, was promising in the attempt to predict the thermal profile of such walls. Alfawakhiri et al. [3] highlighted the dearth in experimental data from full-scale fire testing which hindered the verification and calibration of numerical models. It was recommended that full-scale fire testing of such walls should include detailed measurements of both the thermal and the mechanical behaviour. Sultan and Kodur [5] reported an experimental investigation involving light-weight partition walls constructed using either wood studs or steel studs. A number of important parameters related to such assemblies were experimentally investigated. 
The thermal behaviour of gypsum-faced steel-stud panels were investigated by Feng et al [6]. The panels were square 300 x 300 mm in size representing a small section of a steel-stud gypsum-faced wall. The results of eight fire tests, on such wall panels, were used to calibrate and verify a numerical model for thermal analysis of such panels. The predicted temperatures and calculated temperatures seemed to provide reasonable agreement in some locations but also significant differences at others. It is noteworthy that the research effort presented by Feng et al [6] focused only on the thermal behaviour issues. Feng and Wang [7] carried out experimental study on thinwalled structural panels. The panels were $2.2 \times 2 \mathrm{~m}$ and loaded by a fraction of the ultimate load at ambient temperature. The thermal behaviour was established and the failure mode was noted. Failure as expected occurred as global buckling around the major axis of the stud C-sections. Local buckling in the C-section web was also observed around service opening in the studs. The effect of the stud-thickness on the fire resistance was investigated. It appears that studs with thickness less than $1.2 \mathrm{~mm}$ thick, had poor fire performance. The experimental data collected for panels 2.2 x $2 \mathrm{~m}$ regarding the thermal behaviour together with the thermal bowing behaviour were presented.

Manzello et al. [8] presented data concerned with the consistency of a number of fire certification laboratories in USA, Canada and Japan. The fire test was repeated on full-scale gypsum-faced steel-stud non-load-bearing partition walls. The fire rating of such walls, which was mainly based on the insulation criterion, was compared and found to be similar. There has been significant effort in modelling the thermal behaviour of gypsum-faced wood-stud walls in Canada [3-5] and also in Australia where there has been significant effort in carrying out both thermal and mechanical modelling of wood-studs gypsum-faced partition wall systems [10]. A detailed numerical procedure for predicting the thermo-mechanical behaviour of light-timber framed partition walls was outlined. It is noteworthy that the thermal bowing behaviour of timber-framed walls is fundamentally different from the steel-framed partition walls. Young and Clancy [10] came to the conclusion that the gypsum board on the fire-side did not contribute to the stiffness of the wall 
during the fire exposure and was not included in their mechanical model. However, the gypsum board on the cold-side was included in their thermal and mechanical model. The aim was to capture the additional tensile stiffness of the composite action provided by the gypsum layer on the unexposed-side as the walls bow away from the fire. It is noteworthy that the stiffness of gypsum degraded rapidly after exposure to $100^{\circ} \mathrm{C}$ reaching zero at exposure to $150^{\circ} \mathrm{C}$. The rapid loss of stiffness is caused by calcinations to the hemihydrates. The stiffness of gypsum is negligible when compared to steel at ambient environmental conditions. The elastic modulus of gypsum before any effect of fire was determined as $480 \mathrm{MPa}$, i.e. $0.2 \%$ of the value for structural steel.

The aforementioned research efforts were concerned with the wall systems without the inclusion of doors or openings. Failure of partition walls and doors assemblies to contain a fire by loss of integrity and/or loss of insulation requirement is a very important aspect in fire safety engineering. There is a limited published data related to behaviour of steel doors installed in light walls steelstuds walls. Cooper [11] explored the issue related to how feeling, smelling and visually inspecting a door might indicate whether there is a fire taking place on the other side of such doors. The edges of insulated metal doors and the door-handles areas can provide indicators of possible high temperatures on the opposite side of the door.

Tabaddor et al. [12] reported an investigation into fire performance of a double-leaf steel door in a rigid masonry supporting wall. The complexity and difficulties involved in predicting and validating the behaviour of such door systems were highlighted. The case study reported involved using limited experimental data on a pair of double-leaf steel doors in a rigid masonry wall to validate a numerical model. Capote et al. [13] carried out two fire tests on steel doors with limited data only related to the thermal behaviour of the door-leaf. The temperature measurements on one door opening into the fire were obtained by thermocouples welded to the surface and by 
thermographic images on the other. Thermal displacements and the associated integrity criterion were not reported.

In this paper, the authors expanded the investigation previously reported by Nassif et al. [2] to establish the behaviour of lightweight steel-studs gypsum-faced partition walls when steel doors are incorporated in the test assemblies. There is a dearth of published data related to fire behaviour of steel single-leaf doors installed in lightweight steel studs partition walls documenting both thermal and mechanical behaviour taking into account both insulation and integrity criteria, as well as the effect of cavity insulation in the flexible supporting wall, hence the significance of the data reported here in this paper. 


\section{RESEARCH PROGRAMME}

Fire testing requirements for structural assemblies is mandatory in most countries for certification and fire classification purposes. In the united Kingdom and in accordance with the European code of practice, BS EN 1363-1 [14] provides the general requirements for fire resistance testing while BS EN 1634-1 [15 ] provides the requirement of fire resistance testing of fire doors. Modifications in the wall-door assembly usually require further fire testing or a technical assessment by an accredited fire laboratory. Demand on such laboratories, to carry-out certification tests and technical assessments, is such that a client might have to wait for many months before a test can be scheduled.

The research programme reported here was designed after discussions with fire testing professionals in a number of European countries, namely Switzerland, United Kingdom, and Germany. The programme aimed to investigate structural assemblies involving both masonry walls and lightweight steel-studs gypsum-faced partition walls. The questions related to the fire resistance with respect to both the insulation and the integrity criteria in fire scenarios when the door opens into the fire or opens away from the fire were investigated. The thermal performance and the mechanical behaviour of such assemblies were determined. In this paper, four full-scale fire tests on partition walls incorporating steel doors are reported as outlined in Table 1. 


\section{Table 1}

Full-scale fire tests on steel doors and walls assemblies

\begin{tabular}{|c|c|}
\hline Test Code & Description \\
\hline 1.W2D1-HS & $\begin{array}{l}\text { Steel door in steel-studs wall with wall cavity insulation, opening into the fire. } \\
\text { Door exposed to fire on the hinge-side (HS) } \\
\text { Fire on the hinge-side (HS) }\end{array}$ \\
\hline 2.W2D1-OHS & $\begin{array}{l}\text { Steel door in steel-studs wall with wall cavity insulation, opening away from } \\
\text { the fire. Door exposed to fire on the opposite-hinge-side (OHS) }\end{array}$ \\
\hline 3.W1D1-OHS & $\begin{array}{l}\text { Steel door in steel-studs wall without wall cavity insulation, door opening } \\
\text { away from the fire. Door exposed to fire on the opposite-hinge-side (OHS). }\end{array}$ \\
\hline 4.W4D1-OHS & $\begin{array}{l}\text { Steel door in masonry wall, door opening away from the fire. Door exposed to } \\
\text { fire on the opposite-hinge-side (OHS). }\end{array}$ \\
\hline
\end{tabular}

\section{THE STANDARD FIRE TEST}

The full-scale fire tests conducted during the course of this project were carried out according to the general requirements of BS EN 1363- 1 [14] as well as the specific requirements for fire resistance testing of fire-doors as detailed in BS EN 1634-1 [15].

For the reader convenience, details of the tested walls reported by Nassif et al. [2] during the first phase of this project, are reproduced here and shown in Fig.1. The tested walls were steel-studs gypsum-faced walls built and fire-tested according to BS EN 1363-1 [14] to determine the transient 
thermal and mechanical behaviour during a standard fire test. The 3000 x $3000 \mathrm{~mm}$ wall was constructed within the opening of a concrete frame as shown in Fig.1. U-tracks measuring $75 \mathrm{x} 40 \mathrm{x}$ $0.6 \mathrm{~mm}$ made of galvanised steel were fixed to the top and the bottom of the opening of the concrete frame using screws at $1000 \mathrm{~mm}$ spacing. The entire testing procedure including the properties of the concrete frame, the boundary conditions and the conditioning procedure complied with BS EN 1363-1[14].
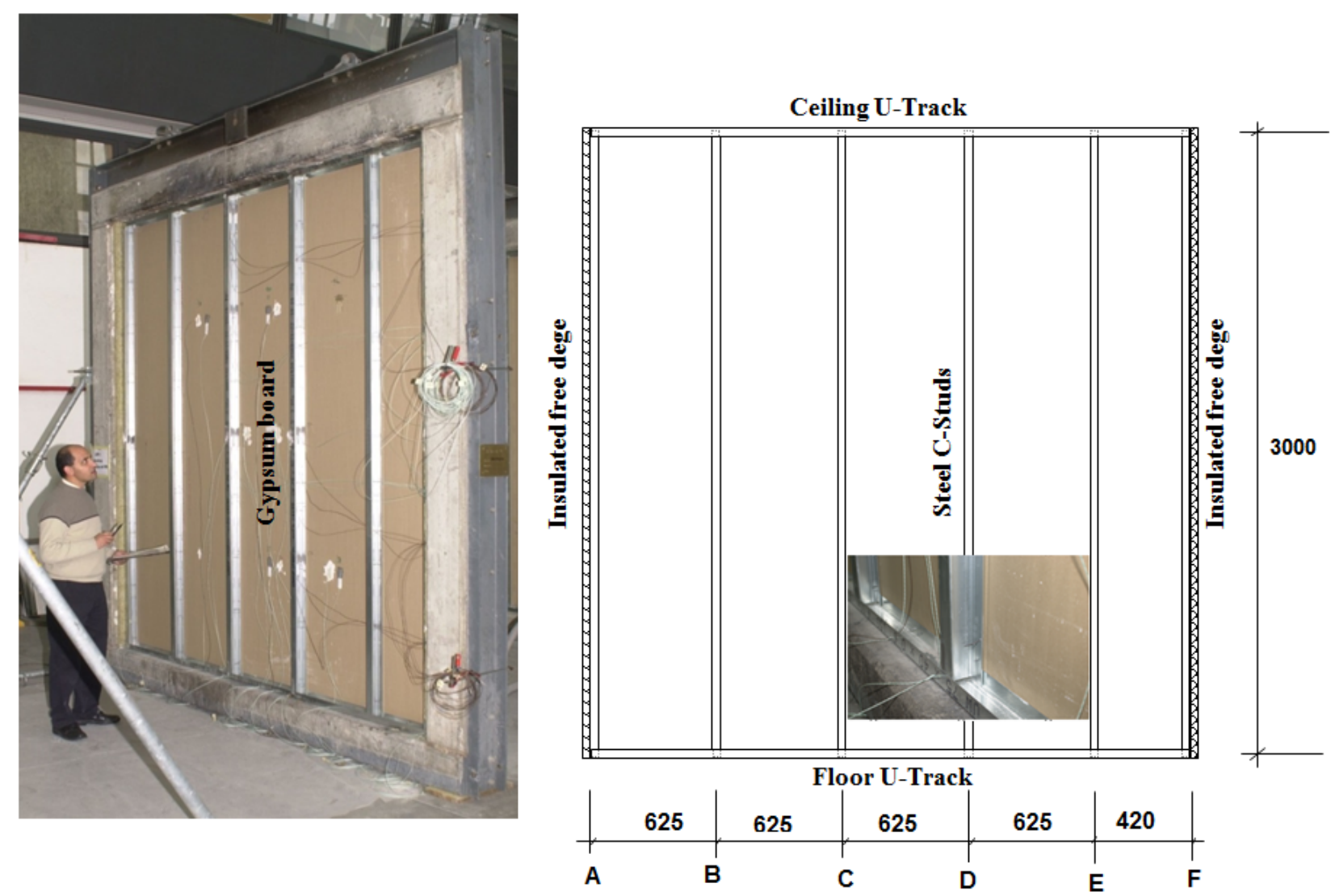

Fig.1. Test wall under construction (Nassif et al. [2])

Each wall incorporated six vertical galvanised steel studs measuring 75 x 50 x $0.6 \mathrm{~mm}$, indicated by the letters A-F in Fig.1, at a spacing of $625 \mathrm{~mm}$ with one end spacing of $420 \mathrm{~mm}$. The vertical steel studs were inserted in top and bottom U-tracks and housed in place initially by friction. There was a gap between the bottom of the stud and the floor U-track of an average value of 
approximately 5 mm. Two layers of gypsum boards (DIN 18180-GKB, EN520 Type $9.1 \mathrm{~kg} / \mathrm{m}^{2}$ ) measuring 12.5 x 1250 x 3000 mm each were installed on each side of the steel studs. The joints in the two layers of gypsum were staggered so that the joints were not on the same steel stud. Each layer of gypsum boards was fixed to the studs using screws 3.5 x $35 \mathrm{~mm}$ at a spacing of $300 \mathrm{~mm}$ along the height of each stud. The gypsum boards were also fixed to the top and bottom U-tracks using the same screws applying spacing of 300, 600, 600, 600, 600, $300 \mathrm{~mm}$ from edge to edge. It is noteworthy that the fixing of the gypsum layers to the top and bottom U-tracks ensured that the vertical studs were not screwed to the top and bottom U-tracks. Rockwool insulation of Knauf type, $40 \mathrm{~mm}$ thick each, were installed into the cavity. The density of the Rockwool was $42 \mathrm{~kg} / \mathrm{m}^{3}$. Both vertical edges of the wall were insulated with the same Rockwool material between the wall and the concrete frame. Therefore the wall was free to deflect perpendicular to the plane of the wall at the vertical edges. The walls were constructed, conditioned and tested according to the requirements of BS EN 1363-1 [14]. All the walls were conditioned for at least 24 hours.

This paper reports the second phase of the project which was concerned with the behaviour of the wall-door assemblies during the standard fire. Fig.2 shows an example of such wall-door assembly with the thermocouple wires ready to be connected to the data-logger for testing the wall-door assembly for exposure to fire on the hinge-side (HS), i.e. the scenario when the door opens into the furnace. The layout and cross-section dimensions of the steel studs used in the case of incorporating the steel door in the wall are also given in Fig.2.

The conditioning of the walls and doors assemblies was carried out according to the requirements of BS EN 1363-1 [14]. The conditioning process aimed at reaching moisture content similar to that expected in normal service. The test pieces were stored in ambient conditions of $23{ }^{\circ} \mathrm{C}$ and $50 \%$ relative humidity. The guidance provided by the informative Annex F from BS EN 1363-1 was taken into account in regard of the conditioning requirements. It is noteworthy that the constituents materials of the tested walls and doors, the gypsum boards and the insulation materials, were also 
conditioned before construction of the test assemblies in the laboratory. The duration of conditioning aimed at reaching moisture equilibrium to a level typical in service conditions. For the materials used in this project, the constituents were stored in the controlled environment of $23^{\circ} \mathrm{C}$ and $50 \%$ relative humidity for a month before assembling the test specimen and for a minimum of a week before the full-scale fire testing took place.

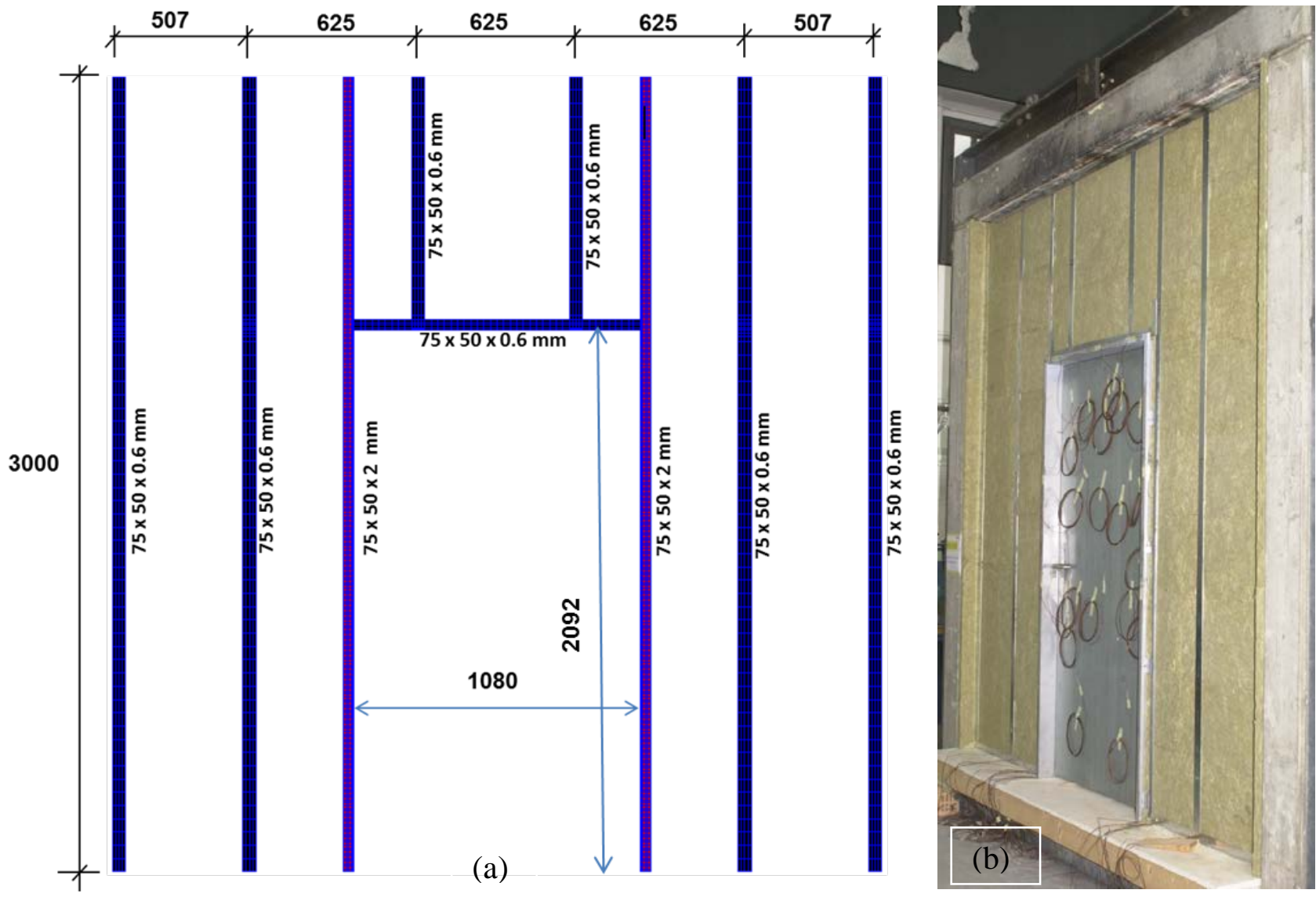

Fig. 2. Wall-door assembly: (a) the general arrangement and cross-section dimensions of the steel studs and (b) the wall-door assembly before the installing the gypsum boards on one side.

In addition to logging the large number of thermocouples during fire test, the mechanical behaviour of the test assembly was measured by recording the deflection and thermal displacements. Fig.3 shows the fire resistance testing set-up. The steel frame, which can be seen in front of the wall in Fig.3, provided the datum for the horizontal displacement caused by the thermal strain gradient. The displacement datum frame complied with BS EN 1363-1[14]. 


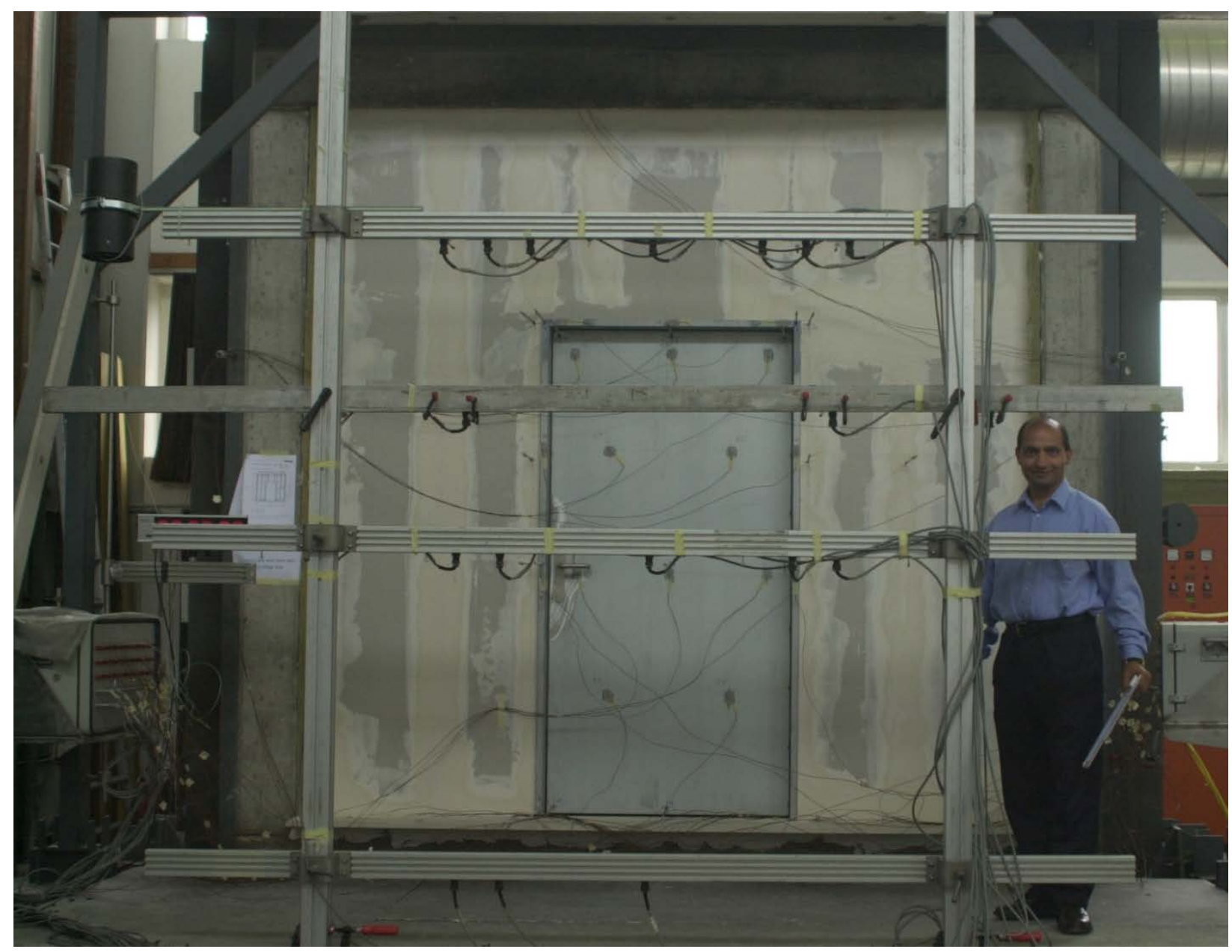

Fig. 3. Full-scale standard fire resistance test set-up.

The furnace gas injection was computer-controlled to follow the time-temperature relationship as given by the standard fire curve. Fig. 4 shows the temperature as given by the standard fire curve (ISO-834) versus the furnace air temperature as measured by the plate-thermocouples in the furnace. The standard fire curve was adopted according to BS EN1991-1-2 [16] and BS EN 1363-1 [14]. 


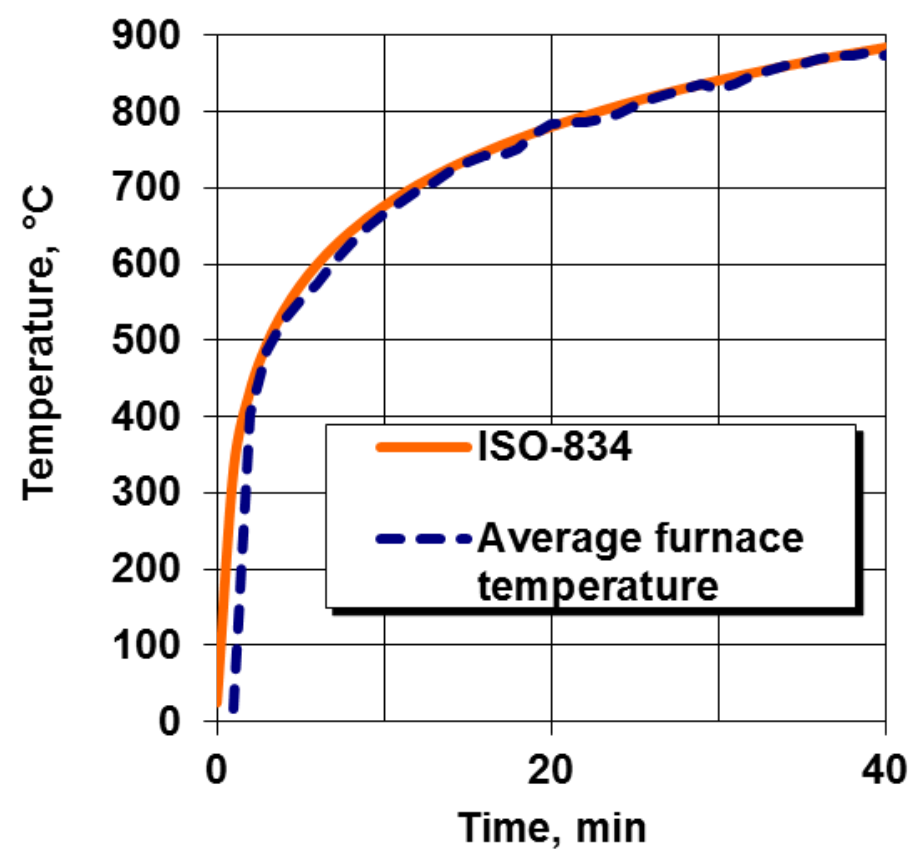

Fig. 4. Standard time-temperature fire curve and average furnace temperatures.

The standard temperature-time curve is a nominal fire curve which is used almost globally to carryout fire resistance tests as set out by BS EN 1363-1 [14]. The standard temperature-time curve is given by the formula:

$\Theta_{g}=20+345 \log _{10}(8 t+1)$

Where:

$\Theta_{g} \quad$ is the gas temperature in the compartment $\left({ }^{\circ} \mathrm{C}\right)$

$t \quad$ is the time in minutes

The standard fire curve presents the post flash-over part of fire development without any presentation of fire decay. It is noteworthy that the European code of practice for structural design makes it possible to adopt a more realistic parametric fire curves for fire structural engineering design. The Eurocodes allow the use of three nominal temperature-time curves, namely: standard 
curve, external curve and hydrocarbon curve. In addition, as a significant departure from the previous prescriptive-based codes of practice, the Eurocodes introduce more realistic fire exposure and consideration of the physical properties of the fire compartment. The concept of equivalent time of exposure is introduced. This relates the real fire exposure to an equivalent duration of the standard temperature-time relationship [17].

\section{STEEL DOOR OPENING INTO THE FURNACE}

The full-scale testing programme was supported by international manufacturers and suppliers of fire doors and partition wall systems. The work reported in this paper is the second phase of the industry-funded project which aimed at collection of experimental data to document the thermal and mechanical behaviour of steel doors and partition walls assemblies during fires.

BS EN 1634-1 [15] outlines the requirements for the direction of fire to establish the fire resistance duration for doors. The scenario of the fire-door opening away from the furnace can cover the integrity criterion required if the fire occurs in the opposite direction, i.e. the integrity criterion for the door opening into the fire. However, the insulation criterion of the door leaf is not covered by the scenario when the door opens away from the fire. Therefore it was decided to test the walldoor assembly in both directions, i.e. with the door opening into the furnace and again with the door opening away from the furnace. The results reported here showed that the direction of fire occurring with the door opening into the furnace is the severest scenario for the insulation criterion of the tested door-leaf as will be reported later. After 30 minutes of exposure to the standard fire, the maximum temperatures recorded on the unexposed door-leaf was $222^{\circ} \mathrm{C}$ and $148{ }^{\circ} \mathrm{C}$ for the two scenarios of door opening into the furnace and door opening away from the furnace respectively. Insulation failure occurred in the case of door opening into the fire as the limit of $180^{\circ} \mathrm{C}$ increase above ambient, given by the fire testing code of practice BS EN 1363 [14], was exceeded after 27 minutes. 
Fig. 5 shows a schematic sketch of the door opening into the furnace together with the thermal considerations. The Gypso-strip, shown in Fig.5, is an intumescent seal all around the top and the vertical sides of the door.

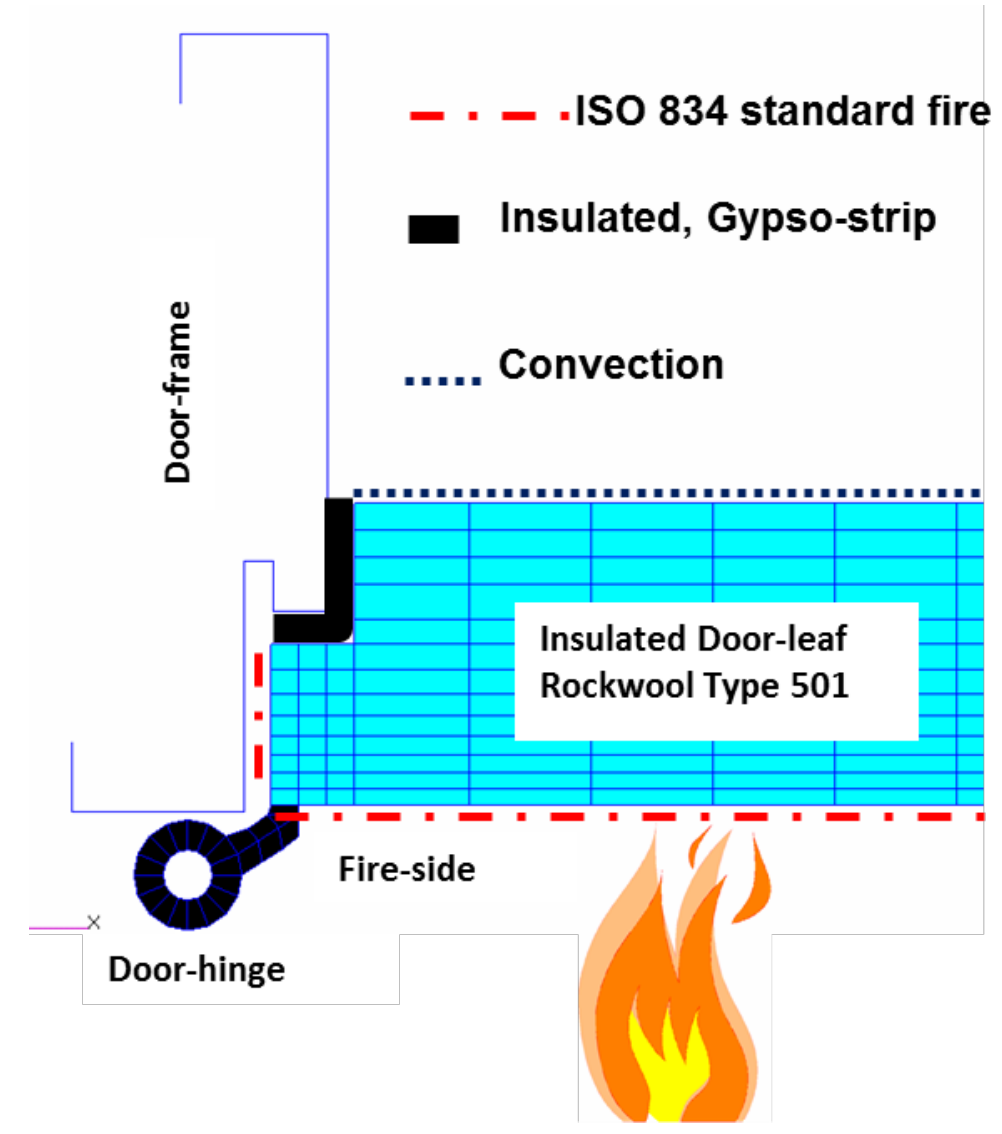

Fig. 5. Fire test for insulation criterion of steel doors opening into fire.

The insulation and integrity requirements of the test assembly are outlined in BS EN 1363-1 [14] and BS EN 1634-1[15]. The insulation criterion for the door-leaf requires that the average increase of temperature does not exceed $140^{\circ} \mathrm{C}$ and that the maximum increase of temperature does not exceed $180^{\circ} \mathrm{C}$. It is worth noting that the limit of maximum temperature rise of the door-frame is $360^{\circ} \mathrm{C}$ according to BS EN 1634-1 [15] . The requirement related to the average temperature rise in the door frame is not clearly defined. Therefore for the insulation criterion of the door-frame only the maximum temperature rise will be considered. 


\subsection{TESTED DOORS}

The test piece, both door and supporting wall, were constructed according to BS EN 1634-1 [15].

The steel door dimensions in elevation and cross section are shown in Fig.6. The thickness of the door was $54 \mathrm{~mm}$. The door-skin was $1.5 \mathrm{~mm}$ electro zinc coated steel sheets (Zintec) grade S330. The $50 \mathrm{~mm}$ thick cavity was filled with Rockwool insulation. The fittings of the tested doors, hinges and locks, were fire-rated to fire resistance of 60 minutes.
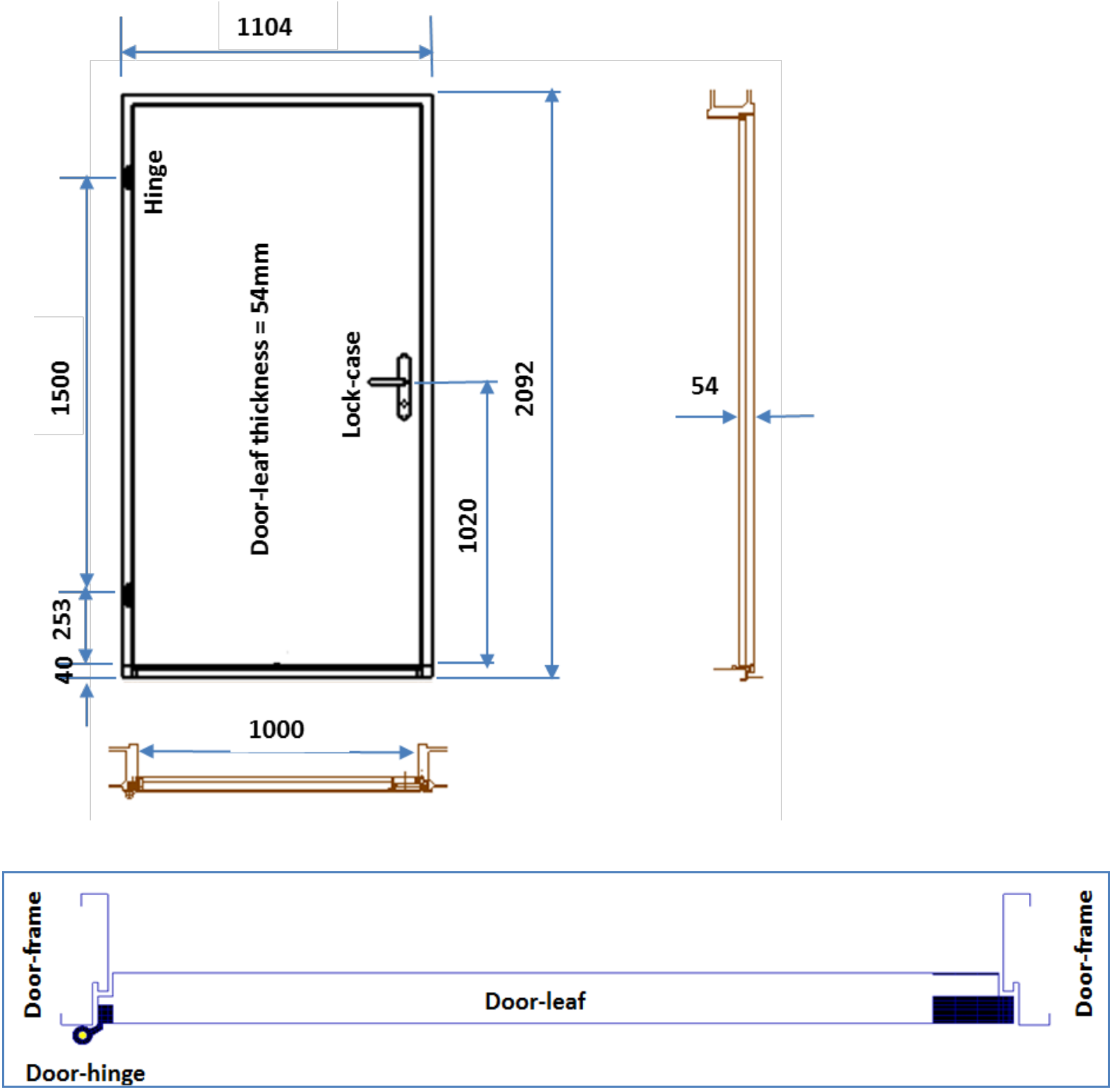

Fig. 6. Dimensions of the test door, $\mathrm{mm}$. 
The door itself was 30 minutes fire resistance rated when installed in masonry supporting wall. However, the behaviour of the door when installed in flexible lightweight steel-studs gypsum-faced partition walls had not been established at the start of the reported phase of the project.

\subsection{OBSERVATI ONS DURI NG THE FI RE TEST}

The thermal and mechanical behaviour of the door was observed, photographed and filmed during the entire duration of the test. Small glass windows at the back of the furnace allowed observations from the fire-side. The door had two hinges, one near the top and the other near the bottom without any other fixings as shown in Fig.6. The lock was located at mid-height of the door-leaf. These were the only geometrical fixations for the steel door system, namely: the two hinges and the lock. Observing from the fire side, the hinges and the lock-case locations started to exhibit some degree of flaming after 15 minutes into the fire test.

The flames moved downward along the hinges-edge of the door reaching the mid-height point where flames were expected to leak as this is the maximum deflection location of bowing into the fire. The "Cotton Pad Test” also failed at 27 minutes when a cotton wool pad placed at the door's mid-height ignited after 16 seconds showing integrity failure.

According to BS EN 1363-1 [14], the fire resistance is generally measured by the duration of exposure to the specified nominal fire until the test piece fails one of three criteria: a) integrity, b) insulation or c) load bearing capacity. The insulation criterion limits the maximum increase of temperature on the unexposed side. The integrity criterion of the fire resistance is defined in BS EN 1363-1 as the duration in minutes for which the test piece maintains its separating function during the test. One obvious loss of integrity is the sustained flaming on the unexposed side. Another way of assessing the integrity is by the cotton pad test which is described in BS EN 13631[14]. A cotton pad is mounted in a frame and placed against the surface of the test piece for a 
maximum of 30 seconds. If the cotton pad ignites that is a measure of loss of integrity. The cotton pad can be placed on the surface of the test piece to achieve maximum effect from the hot gases. The partition walls and doors assemblies investigated during this project were non-loading bearing systems, hence only the integrity and insulation criteria of fire resistance were considered.

After 27 minutes into the fire test, the flames leaked to the unexposed side causing the door to fail the integrity criterion as shown in Fig.7. Analysis of the thermal measurements on the unexposed surface of the door showed that the door also failed the insulation criterion after 27 minutes as will be detailed in section 4.3 .

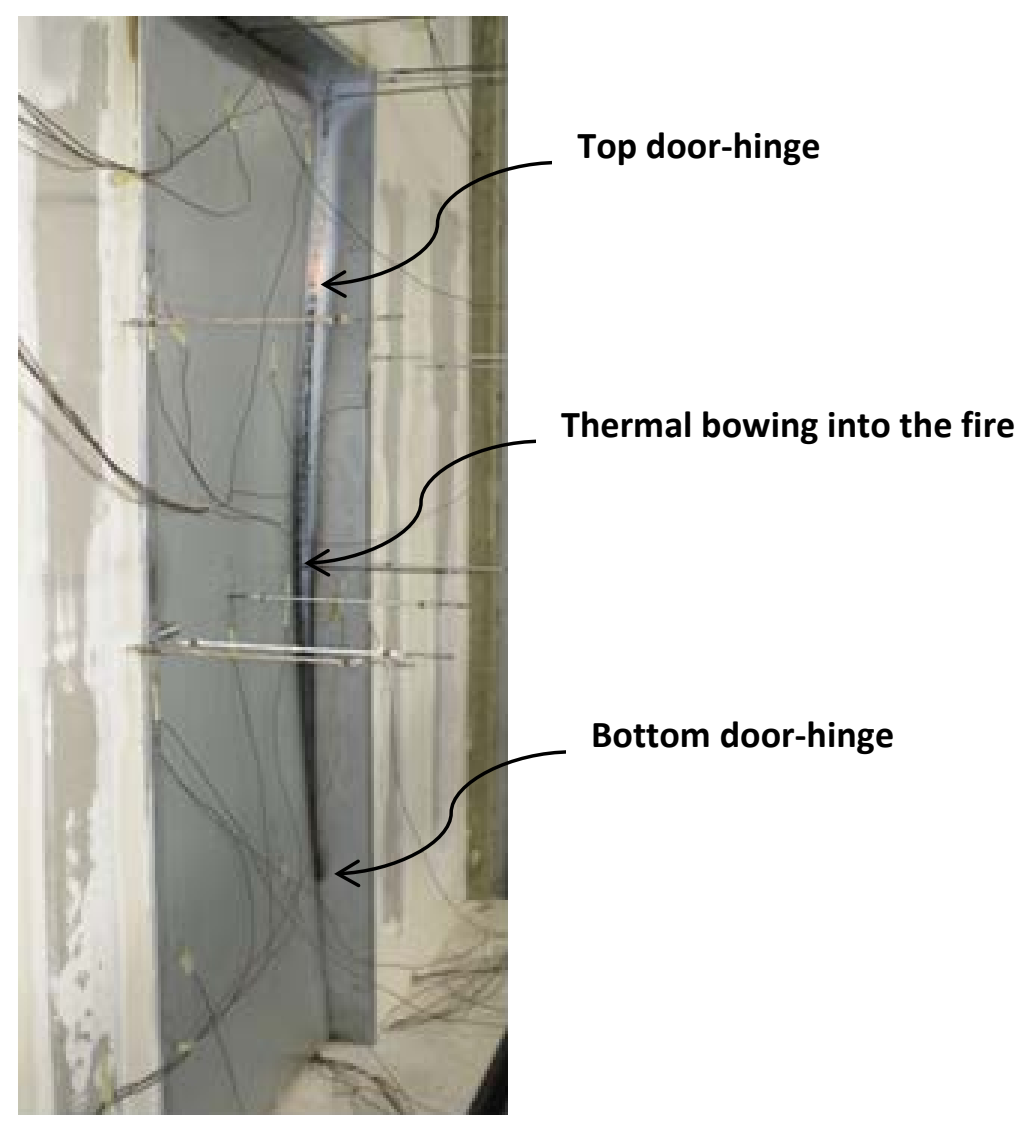

Fig. 7. Fire test of steel door exposed on the hinge-side (HS).

During exposure to fire on the hinge-side, the integrity failure of the steel door-leaf occurred by flame leakage near the top of the door first then by flame spreading down to mid-height where the thermal bowing into the fire was maximum value of $55 \mathrm{~mm}$ after 30 minutes exposure to the 
standard fire. An additional geometric fixation at mid-height of the door could have significantly enhanced the fire resistance of the assembly.

Following the fire test a post-fire examination took place to visually assess the thermal and mechanical behaviour. Thermal exposure was visually assessed by observing discoloration and texture of the door surface. On the fire exposure side of the door, there was severe discoloration with various intensity indicating non-uniform heating. The lock-case edge of the door showed interesting pattern of deformation. The interaction between the door and the wall was apparent. As the wall bowed into the fire it pushed the door-edge in a cantilever action into the fire as well. This was opposite to the direction of thermal bowing of the edge above the lock-case. This is an example of the importance of the interaction between the door and the wall and how the overall behaviour of the assembly is affected.

\subsection{THERMAL BEHAVIOUR}

Fire exposure on the hinge-side, i.e. door opening into the fire was found to be the severest exposure condition for the door-leaf with respect to the insulation criterion. The door-leaf and doorframe were instrumented with thermocouples on the unexposed side as required by BS EN 1363-1 [14] and BS EN 1634-1 [15]. Fig.8 shows the location of thermocouples, indicated by the letter T, on the unexposed side of the door-leaf and door-frame. 


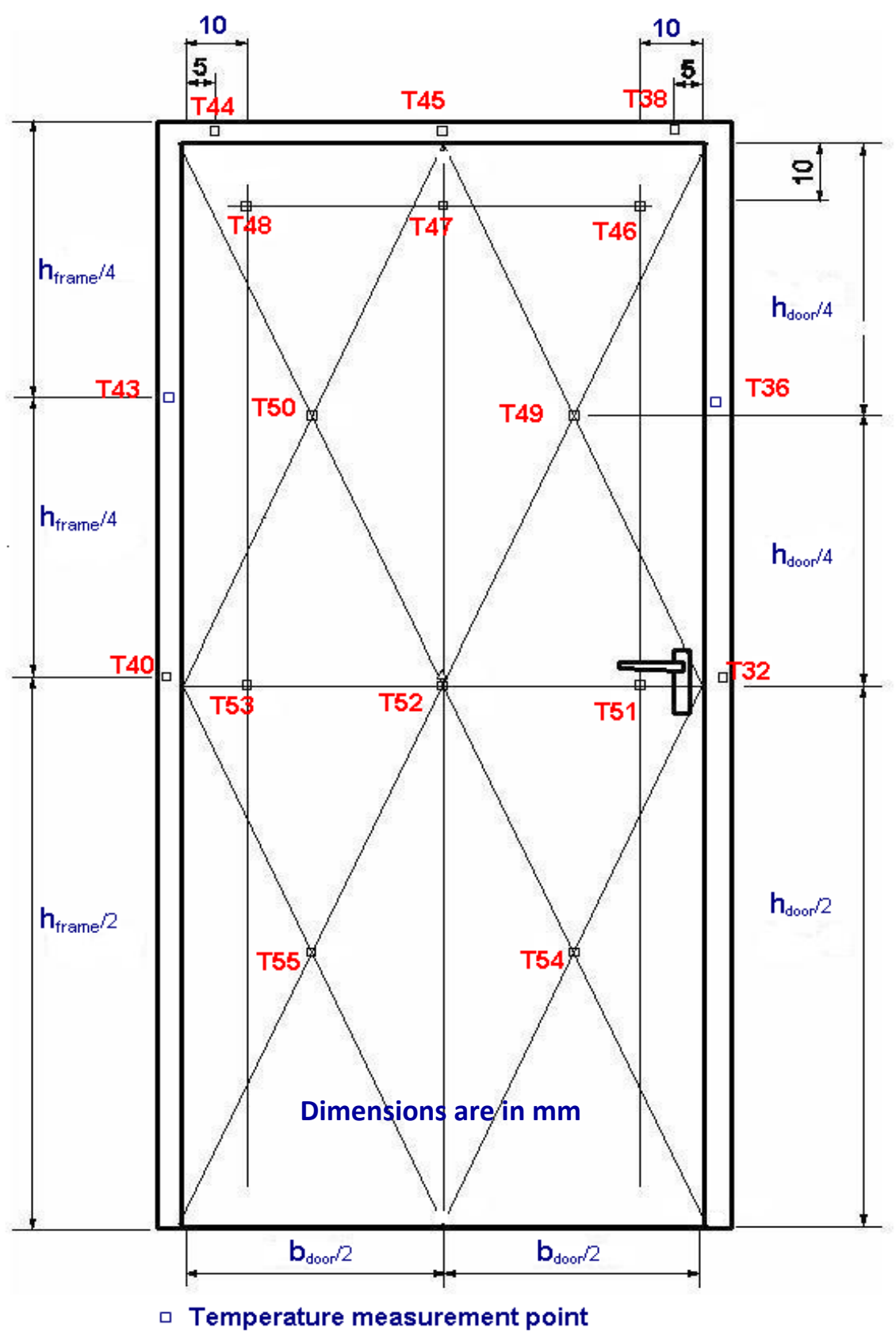

Fig. 8. Locations of the thermocouples on the unexposed side of the door-leaf and door-frame.

Fig.9 shows the recorded temperature on the unexposed door-leaf. The average temperature of the door-leaf increased by $128^{\circ} \mathrm{C}$ after 30 minutes exposure. This is within the requirement for insulation of a maximum average increase of $140^{\circ} \mathrm{C}$. However, the maximum temperature occurred at location T46 reaching $215^{\circ} \mathrm{C}$, i.e. an increase above ambient of $195^{\circ} \mathrm{C}$ at 30 minutes well in excess of the limit of $180^{\circ} \mathrm{C}$ for insulation criterion [14,15 ]. As one would expect, the 
minimum increase in the unexposed side temperature occurred in the middle of the door at location T52. It is evident that the energy supply to the unexposed side is somewhat disrupted at about 10 minutes.

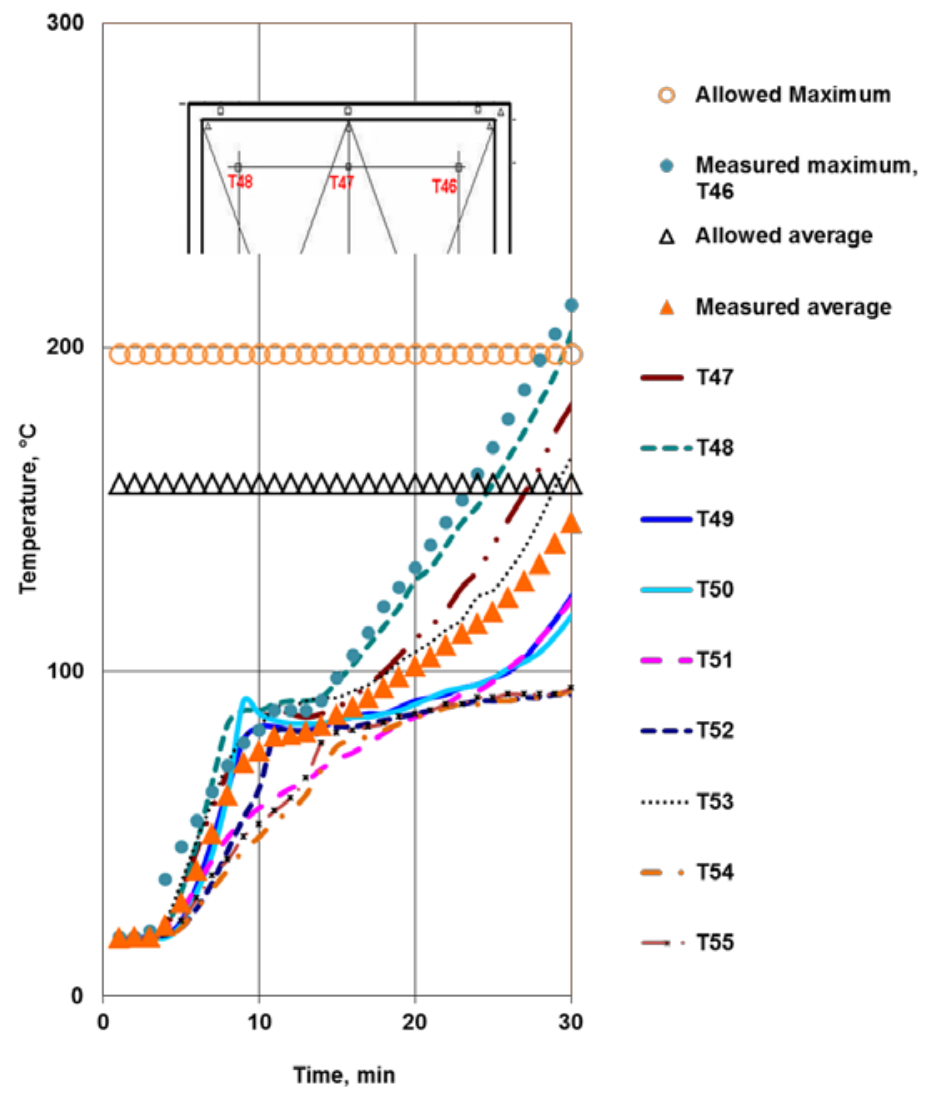

Fig. 9. Temperature on the unexposed side of steel door heated on the hinge-side.

The changes in the temperature of the unexposed side of the door-leaf are determined by a number of factors including the conductive heat, the convective heat, the geometric features, the mechanical displacement behaviour of the entire door-leaf and/or the local buckling characteristics of the steel door skin. In addition, the possible release of moisture from the insulation material in the cavity of the door-leaf at about $100^{\circ} \mathrm{C}$ plays a part as well. Fig.10 compares the temperature measurements by thermocouples T46, T51, T52 and T53 on the unexposed side of the door-leaf when the fire occurs on the hinge side (door opens into the fire compartment). The conductive heat flow to location T46 at the top corner exhibited the maximum temperature increase on the unexposed surface of the door-leaf. This is expected as the heat flows from both the vertical side edge and the horizontal top edge of the door to this location. There is a disruption to the energy supply at about 
$100^{\circ} \mathrm{C}$ which could be attributed to moisture release from the door-leaf cavity insulation. The measurements recorded by T53 are affected by the conductive heat through the door leaf-skin. In addition, the temperature recorded by T53 is affected by the thermal bowing into the fire which exhibited maximum values near location T53, as shown in Fig.7. While location T53 exhibited maximum door-leaf displacement, T51 location was restrained from lateral displacement, relative to the door frame, by the door-lock. In addition, T51 was located near the door-lock which resulted in heat energy dissipated in and through the door-lock mechanism. The temperature measurements of T52 provide some indication of the effect of local buckling of the steel door skin at location T52. The post-fire examination of the door-leaf showed clear evidence of local buckling of the unexposed door skin at location T52 resulting in the formation of gaps behind this location in the door cavity. The separation of the unexposed door skin from the door cavity insulation together with the release of moisture at $100^{\circ} \mathrm{C}$, contributed to the pronounced plateau in the temperature measurements recorded by T52.

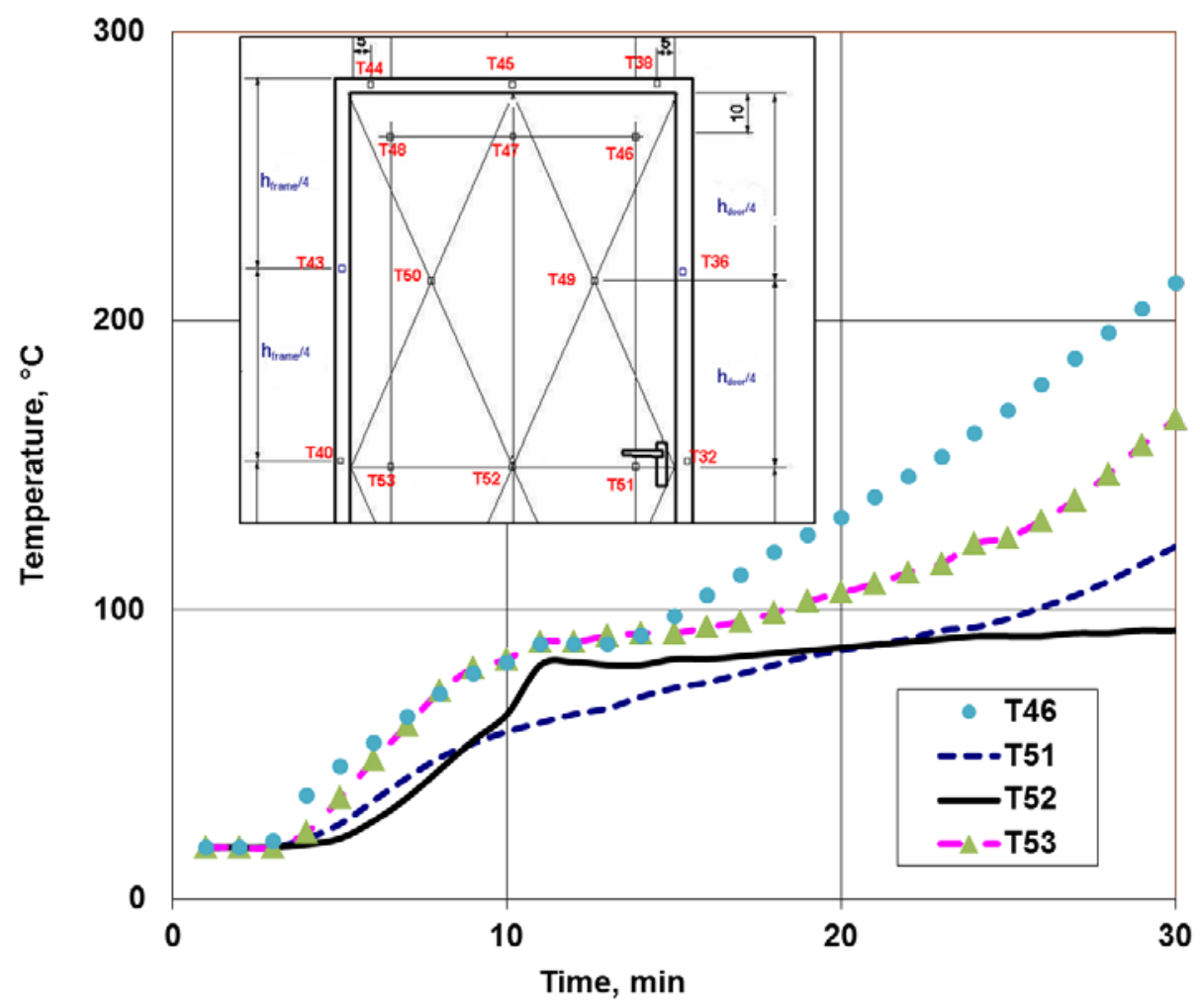

Fig. 10. Comparison between T46, T51, T52 and T53. 


\subsection{DEFORMATI ON CHARACTERI STI CS}

The thermal bowing of the door was measured at 18 locations indicated by V1 to V18 in Fig.11.

The maximum deflection was recorded, as expected, at location V10 (mid-height, hinges-edge), as shown in Fig.12. Thermal bowing of the door-leaf into the fire between the two hinges was observed even at the initial stages of the fire. The interaction, contact and relative movement between the assembly components influenced the mechanical behaviour and the fire resistance of the assembly. The steel studs, to which the door frame was fixed, bowed towards the fire. The relative movement between the door-leaf and the door-frame, i.e. the difference between V10 (located on the door-leaf) and V18 (located on the door-frame) is the most relevant displacement in this case. Fig.12 shows that the maximum deflection at door mid-height between the hinges, reached $55 \mathrm{~mm}$ after 30 minutes. The maximum deflection relative to the wall, (V10- V18), was 43 $\mathrm{mm}$, as shown in Fig.11. It is also noteworthy that the deflection at location V1 in the centre of the door indicates buckling behaviour as early as 3 minutes from start of the fire.

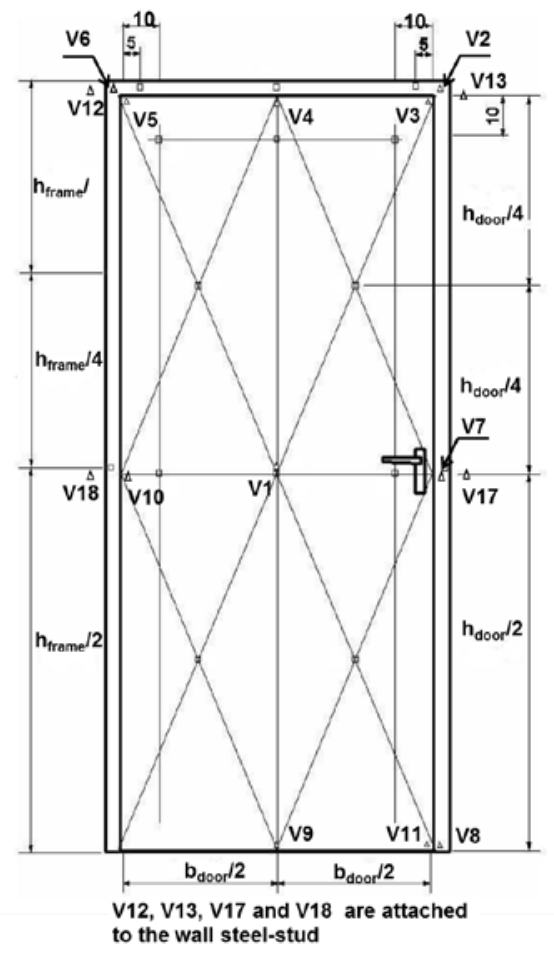

Fig. 11. Locations of displacement measurements of the thermal bowing of the door and surrounding wall. 


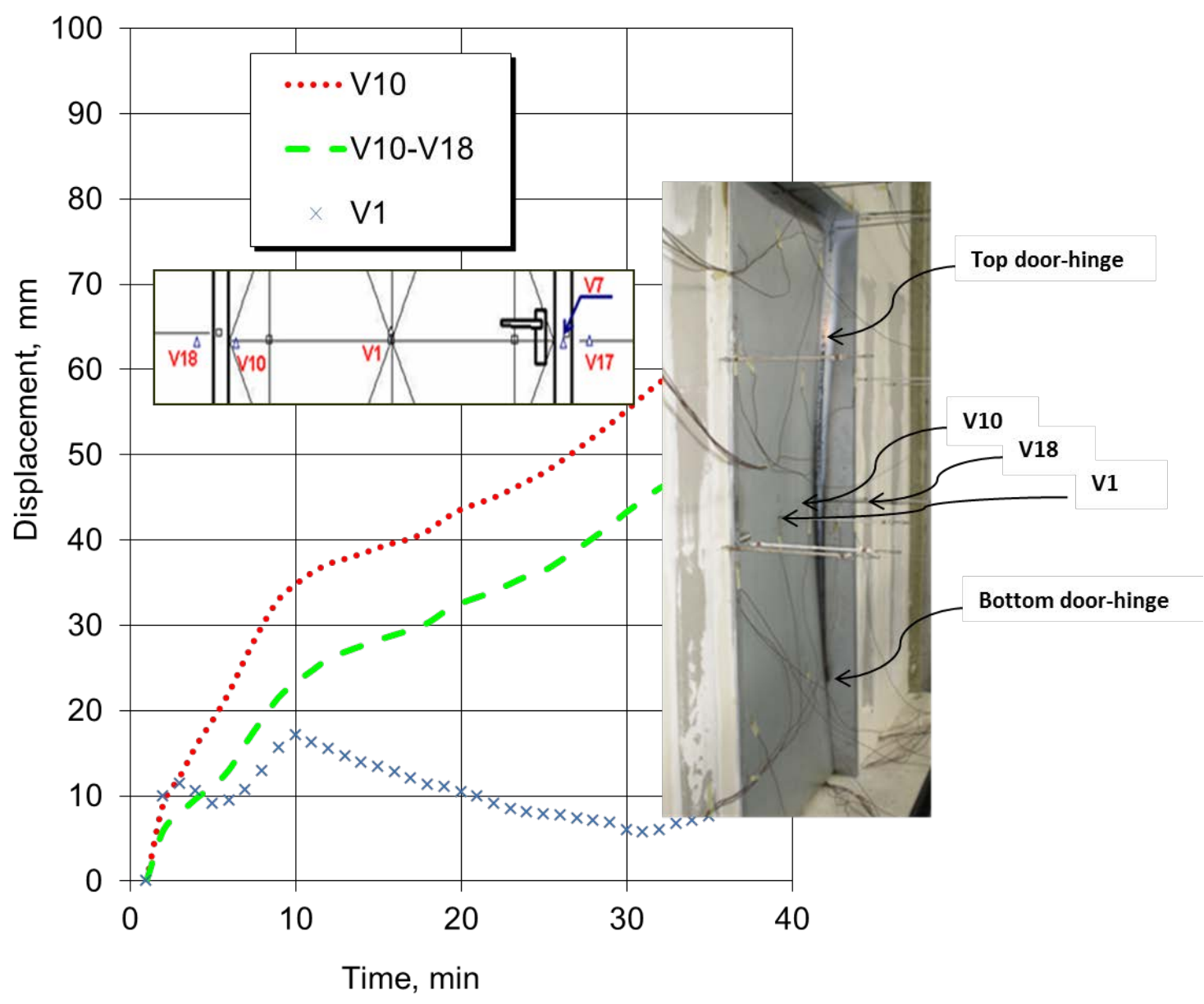

Fig. 12. Thermal bowing measurements of steel door exposed to fire on the hinge-side.

\section{STEEL DOOR OPENING AWAY FROM THE FURNACE}

The European code of practice for fire certification of doors, BS EN 1634-1[15], requires testing of hinged metal-leaf doors with the door opening away from the furnace to establish the fire resistance duration according to the integrity criterion. The displacement behaviour, mainly thermal strain, is critical as the corners above and below the lock exhibit critical movement relative to the frame as shown in Fig.13. This could lead to integrity failure as flames and/or hot gases leak to the unexposed side. This scenario of fire exposure test, with the door opening away from the fire, was repeated 3 times. In two of the tests, the supporting wall was constructed of steel-studs and gypsum 
boards. In one test, the wall cavity was insulated with Rockwool. In another test, the wall cavity did not include any insulation. The third test was carried out with the door supported in a masonry wall. All test doors and walls assemblies were constructed and tested according to BS EN 1634-1 [15].

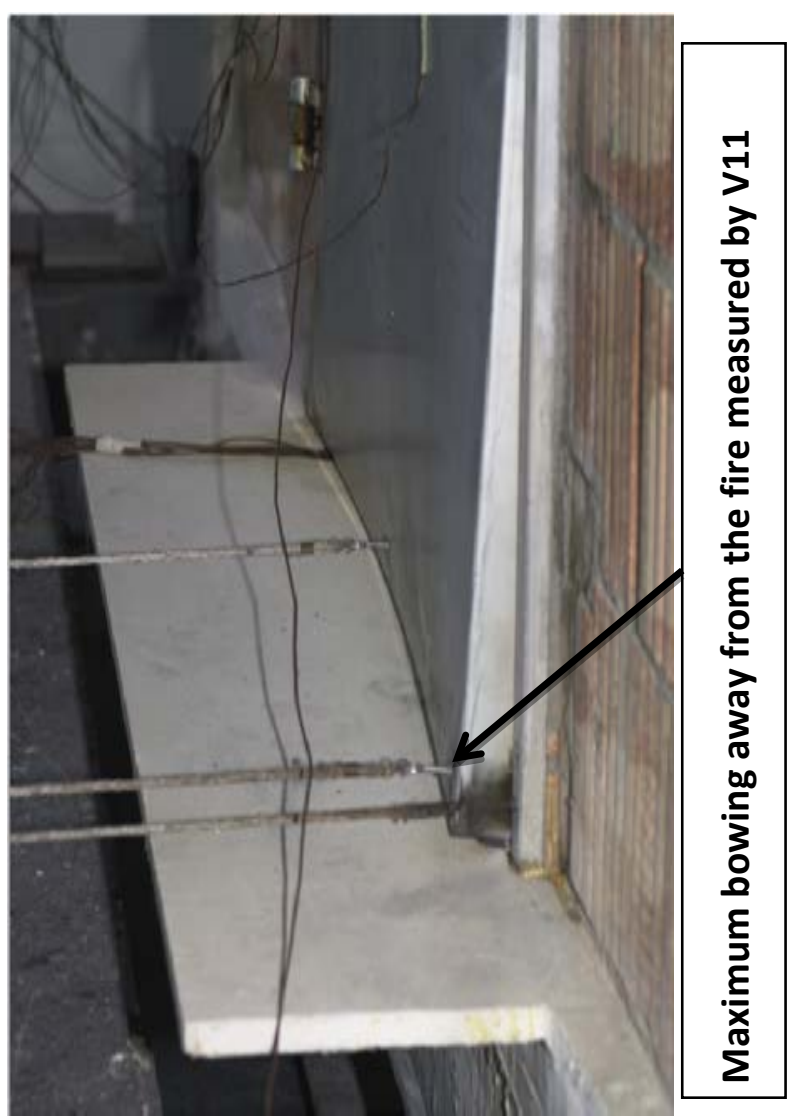

Fig. 13. Thermal bowing during exposure to fire on the opposite-hinge-side (OHS).

The performance of the lightweight wall, which included cavity insulation with the steel door exposed on the opposite-hinge-side, showed obvious bowing away from the fire by approximately $10 \mathrm{~mm}$ after 4 minutes from the start of the test. Smoke started to leak from location of the maximum deflection, V11, after 15 minutes into the test. The "cotton pad test” showed integrity failure near location V11 of the maximum deflection. Post-fire examination of the door, which took place after the door cooled down, showed interesting residual deformation in the frame. It was 
obvious that the frame sagged at the top edge and deformed in a similar manner to a vertically loaded portal frame as shown in Fig.14.

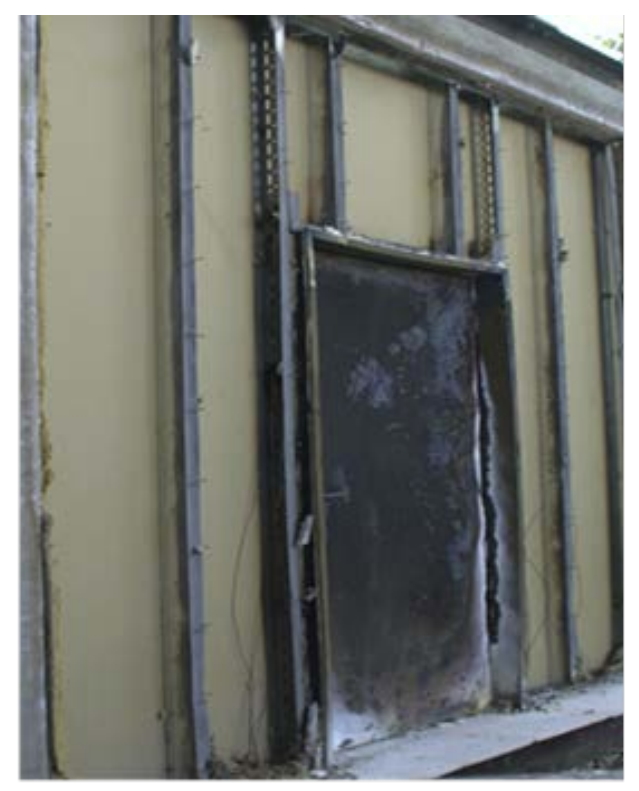

Fig. 14. Post-fire examination of a steel door after exposure to the standard fire.

This had implication with respect to the opening of a gap between the door-leaf and the door-frame along the edges. The door-leaf skin near the sagging top edge of the door exhibited buckling behaviour. Examples and evidence of complex interactions between the various components of the door assembly were observed. The residual deformation of the exposed door-skin showed irregular patterns of local buckling. The unexposed door-skin showed more uniform residual deformation with maximum value in the middle of the door as one would expect.

\subsection{THERMAL BEHAVI OUR}

For this scenario, the door installed in an insulated wall and the door-leaf opening away from the furnace (W2D1-OHS), the temperature measurements on the unexposed side of the door-leaf (T48T55) together with the average measured temperature as well as the limiting value according to BS EN 1634-1 [15] are presented in Fig.15. When these values are compared with the corresponding values presented in Fig.9 for the scenario of the door opening into the furnace, it is clear that the 
scenario of the door opening into the furnace is more critical for the insulation criterion of the doorleaf. The location of the intumescent fire strip which was shown in Fig.5, resulted in larger area of exposure to the fire as well as shorter conductive length in the scenario of fire taking place on the hinge side of the door.

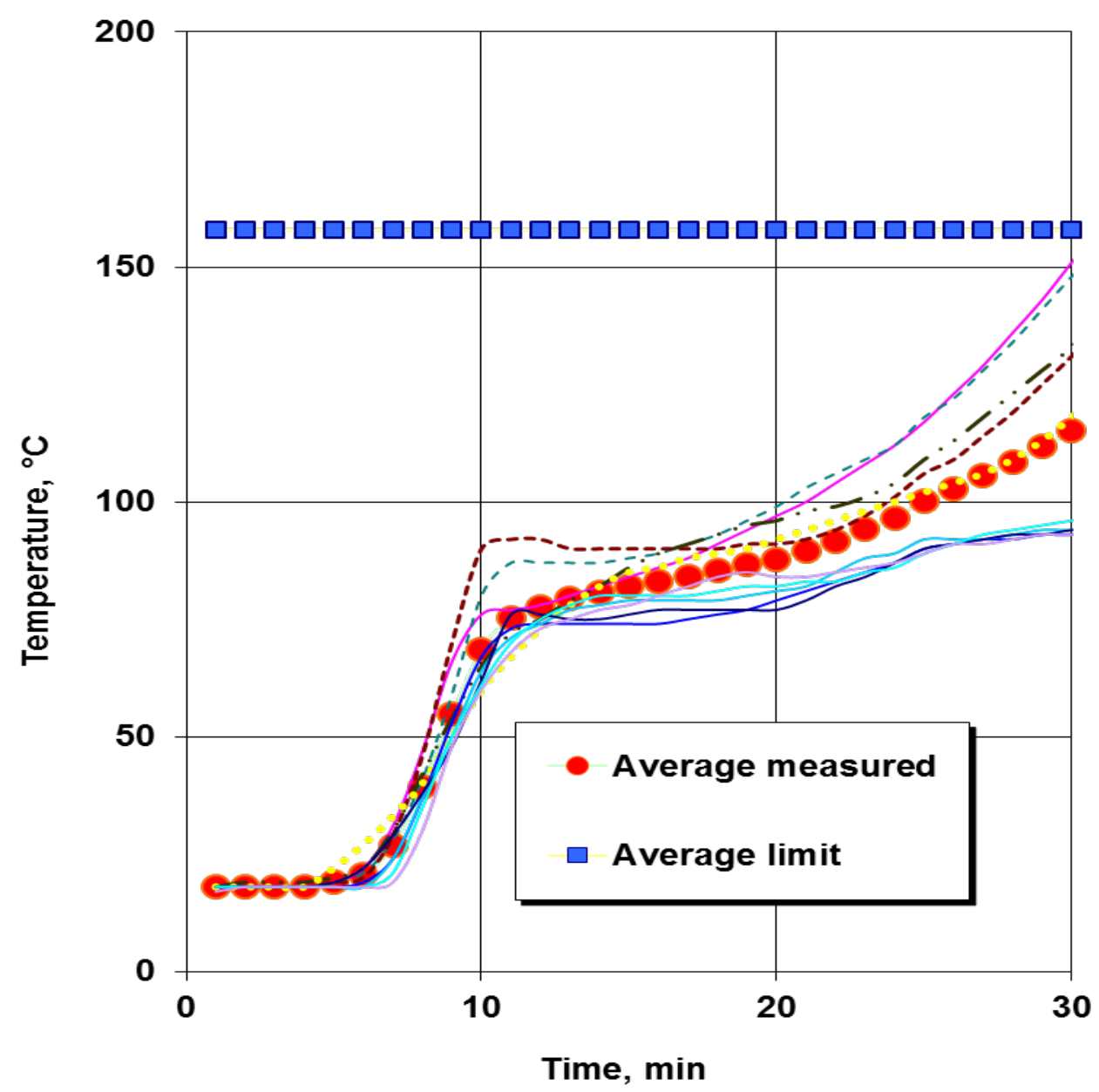

Fig. 15. Measured temperatures on the unexposed side of a door-leaf during fire exposure on the opposite-hinge-side (W2D1-OHS). 
However, the scenario when the door opens away from the fire could be critical for the door frame as it involves heating larger area of the door-frame and shorter conductive length. The door-frame temperatures were recorded for locations T44, T45, T38, T43, T36, T40 and T32, as defined in Fig.8. The average door-frame temperatures reached the allowable average increase of $140{ }^{\circ} \mathrm{C}$, according to BS EN 1634 after 19 minutes. However, the maximum increase was well below the allowable maximum increase of $360^{\circ} \mathrm{C}$ as shown in Fig.16. It is not clear in BS EN 1634-1: 2000 clause 11.2.3 whether the limiting average applies for door-frames. However, the code is clear about the limit of the maximum temperature of the frame being limited to $360^{\circ} \mathrm{C}$ for the insulation criterion of the door-frame.

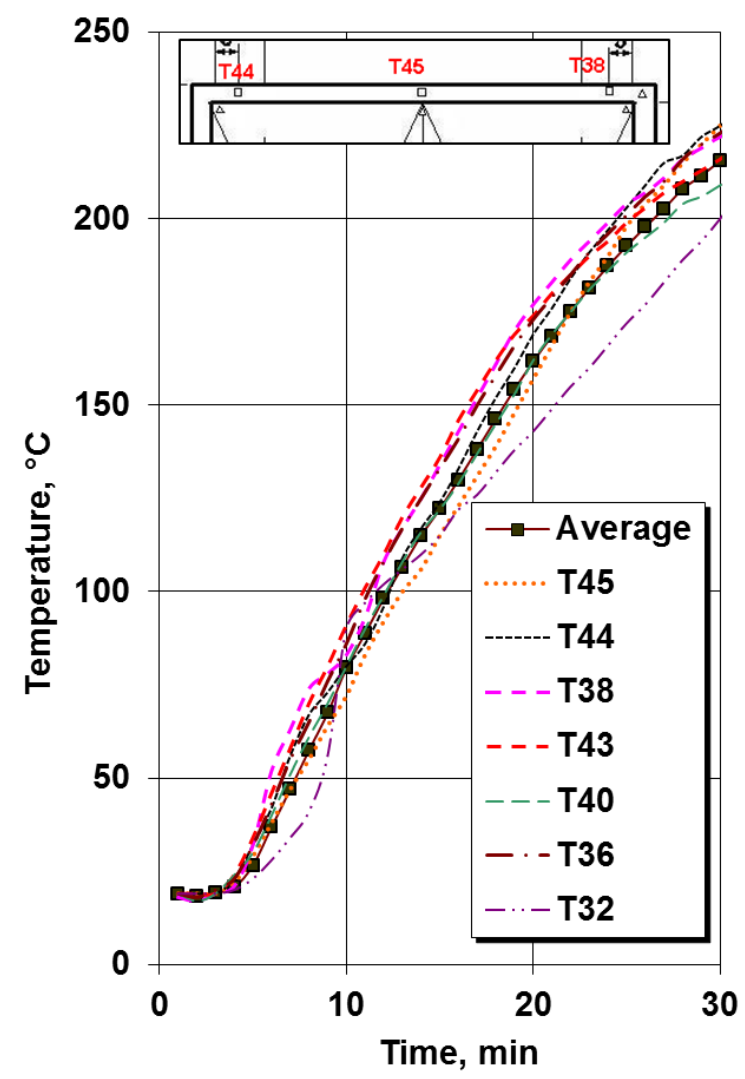

Fig. 16. Door-frame temperatures during exposure to fire on the opposite hinge side. 


\subsection{DEFORMATI ON CHARACTERI STI CS}

The displacements of the door-leaf, the door frame and the surrounding wall were measured in the direction perpendicular to the plane of the wall at 18 locations as shown in Fig.11. The door corners above and below the lock are free to bow away from the fire in this test scenario of the door opening away from the furnace. The edge of the door, where the lock is, behaves in a cantilevered action from the fixed lock location. Fig.17 shows that the door-frame bowed away from the fire at location V2 (frame displacement) while the wall bowed into the fire at location V12 (wall displacement) leaving a gap between the wall and the frame. The displacement of the top corner of the door, above the lock, was monitored by V3. After 30 minutes of exposure, the relative movement between the door-leaf and door-frame (V3-V2) was $12 \mathrm{~mm}$ away from fire, while the absolute displacement of the door, as measured by V3, was $17.4 \mathrm{~mm}$. Such behaviour seems to be beneficial as integrity is expected to be affected by the relative movement between the door-leaf and the door-frame rather than the actual movement of the door.

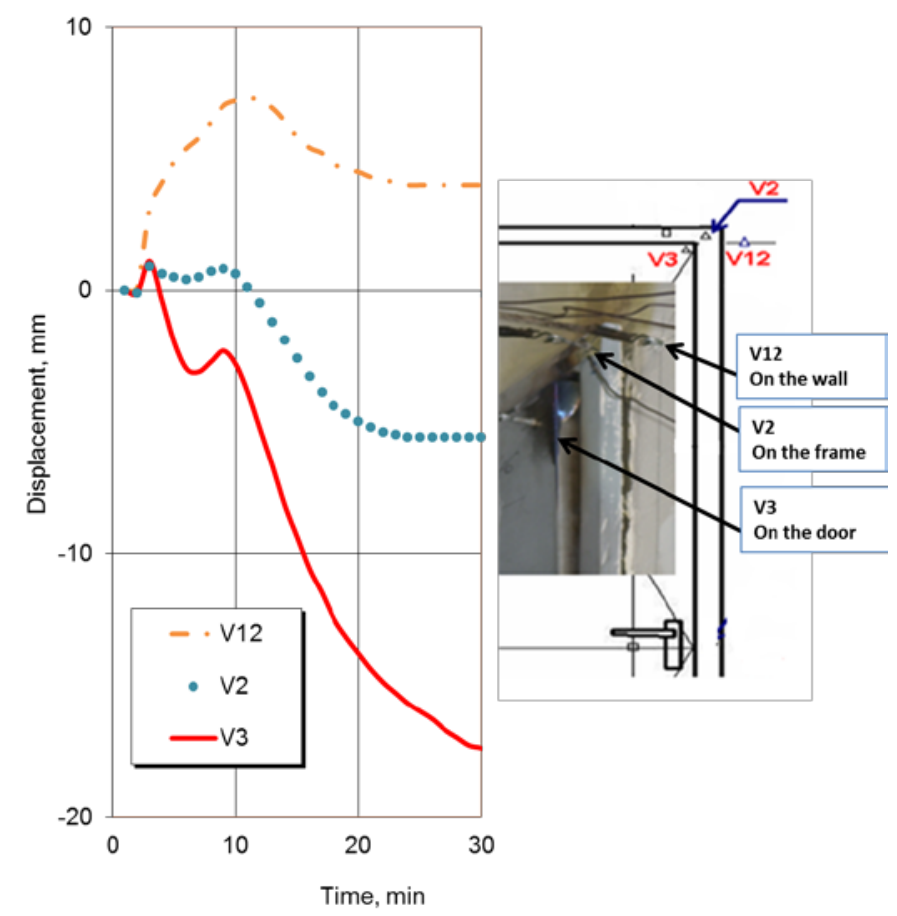

Fig. 17. Relative thermal bowing at the top of the door-leaf and the door-frame. 
It was apparent that the maximum relative deflection will take place at location V11 at the bottom edge, as shown in Fig.18. It is noteworthy that the integrity failure at 19 minutes (in the case of the wall with the cavity insulation) by the ignition of the cotton pad is associated with a thermal deformation of 30 mm away from the fire as measured by V11 and shown in Fig.18.

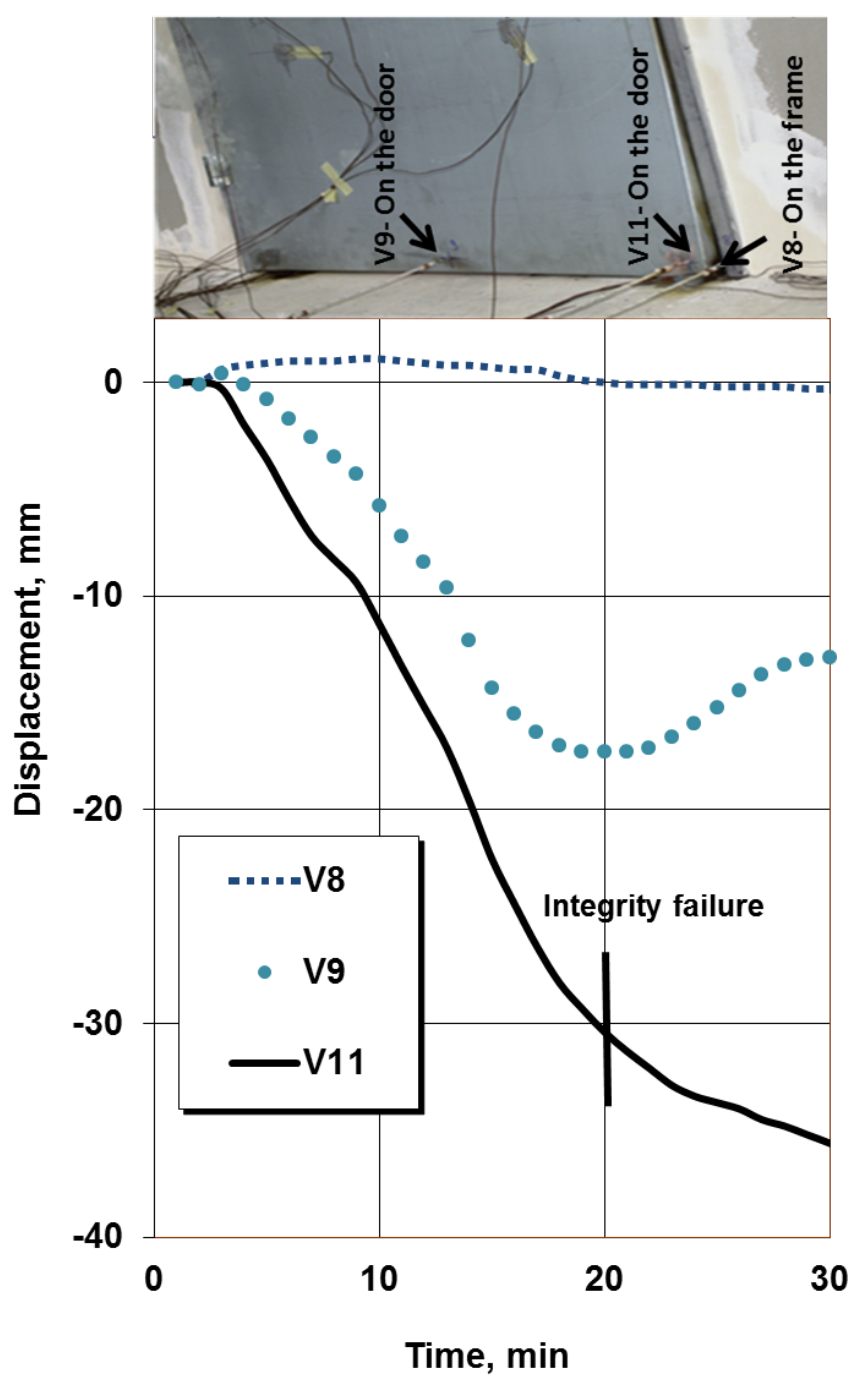

Fig. 17. Thermal bowing at the bottom edge of the door. 


\section{COMPARISON BETWEEN THE FOUR FULL-SCALE TESTS}

Fig.19 and Table 2 summarize the experimentally determined fire resistance durations for the steeldoors and partition walls assemblies under fire scenarios as described in Table 1. The location of integrity failure is also indicated. The interaction between walls and doors and the influence of this interaction on the fire rating of doors is significant.

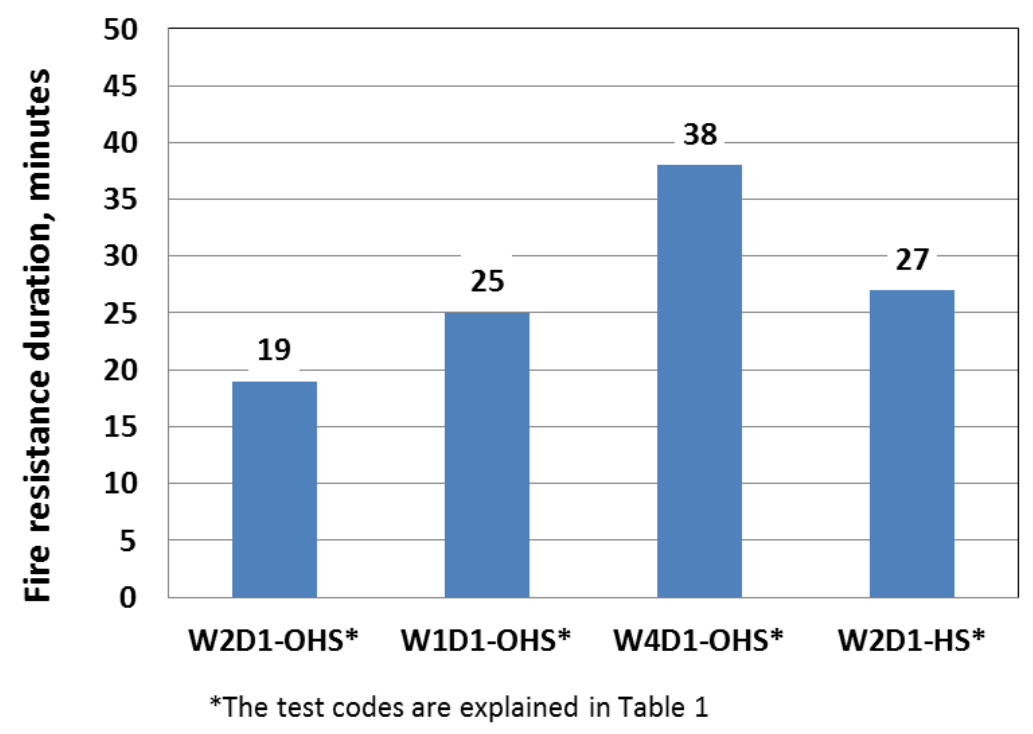

Fig. 19. Comparison between the performances of the door-wall assemblies

The scenario when the fire took place on the hinge-side (W2D1-HS) resulted in simultaneous loss of insulation and integrity after 27 minutes exposure to the standard fire. For the door tested on the hinge-side, the top-hinge location started to exhibit flame leakage before the location of maximum bowing at mid-distance between the two hinges. The steel doors installed in two steel-stud gypsum-faced walls with wall cavity insulation (W2D1-OHS) and without wall cavity insulation (W1D1-OHS) achieved fire resistance, based on the integrity criterion of, 19 and 25 minutes respectively. The reduced duration of fire resistance of the door in the insulated wall, when the door opens away from the furnace, is explained by the steeper thermal gradient in case of wall cavity insulation. The steeper gradient of thermal strain resulted in larger thermal bowing of the wall leading to larger relative displacement between the door and the wall, hence the reduced fire 
resistance of the door-leaf in the insulated wall compared with the door in the wall without insulation. This finding could have implications with regard to the European code of practice for fire certification. The steel door installed in the rigid masonry wall (W4D1-OHS) performed relatively well achieving 38 minutes fire resistance.

The thermal bowing of the steel-studs gypsum-faced partition walls was investigated by Nassif et al [2] during the first phase of this research project. The magnitude of the thermal bowing is determined by the thermal strain gradient which is a function of the temperature gradient. In such light-walls systems, the steel studs provide most of the stiffness of the wall. The gypsum boards provide negligible contribution to the stiffness, particularly at elevated temperatures, as reported by Nassif et al [2]. The thermal gradient through the steel studs is a major determinant in the deflection characteristics of such systems during exposure to fire, as one would expect. During the first phase of the project [2], two steel-studs gypsum-faced partition walls were exposed to the standard fire test. One wall was constructed without cavity insulation while the cavity of the other wall was filled with Rockwool insulation. Fig. 20 shows that the insulated wall exhibited significantly increased thermal bowing into the fire compartment than the wall without any cavity insulation. This is explained by the higher thermal gradient across the wall when the cavity is insulated than when the cavity is empty.

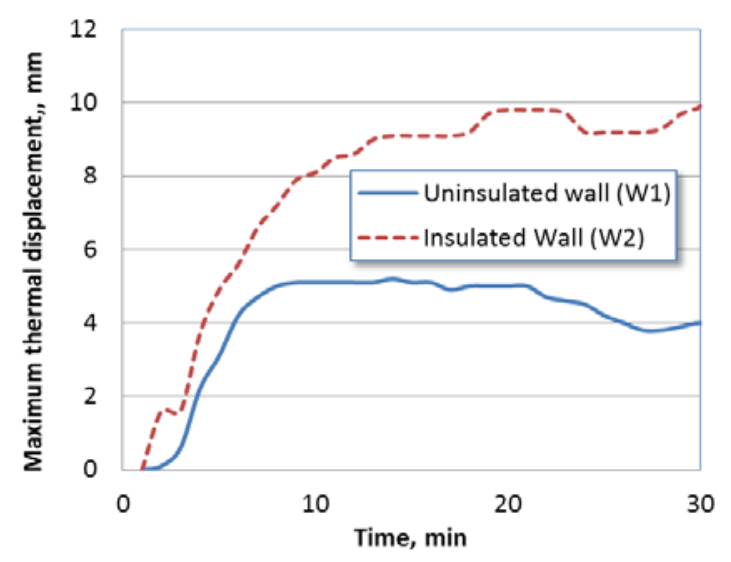

Fig. (20) Comparison between the maximum deflection behaviour of insulated and non-insulated walls. 
The masonry wall possessed comparatively much higher bending stiffness due to the higher moment of inertia (second moment of area) of the masonry wall cross-section than the thin steel studs (0.6mm thick) in the light-walls assemblies, as detailed by Nassif et al [2].

It is clear that whether the door-leaf opens into or away from the fire compartment is an important factor in determining the fire resistance of such systems. The thermal and mechanical behaviour of the door-leaf during exposure to the fire is different when the fire occurs on the hinge-side or on the opposite-hinge-side. This can be explained with reference to the geometry of the door-leaf and the door-frame assemblies as shown in Fig. 5 and Fig. 6. The higher thermal strain on the side of the door-leaf exposed to the fire together with the characteristics of the geometric constraints provided by the door-hinges, door-lock and/or the door-frame, play a major role in the displacement characteristics of the door-leaf during exposure to the fire and hence its fire resistance. For example when the door-leaf opens into the fire (exposure on the hinge-side), the lock-edge of the door deflects towards the door-frame closing the gap between the door-leaf and the door frame at the lock-edge of the door-leaf. This behaviour is entirely different when the door-leaf opens away from the fire (exposure on the opposite-hinge-side). The lock-edge of the door-leaf exhibits deflection away from the frame with maximum value at the bottom of the door as shown in Fig. 17. The thermal behaviour and the heat transfer through the skin of the door-leaf is also affected by whether the door opens into or away from the fire compartment as the exposed surface area and the conductive length is different in both cases, as shown in Fig. 5. It is noteworthy that the intumescent strip between the door-leaf and the door-frame (the Gypso-strip in Fig.5) stops direct exposure to the fire on the area where the Gypso-strip is applied, contributing to the difference in the thermal behaviour between the two scenarios of fire exposure. 
Table 2 Fire resistance durations and limiting fire resistance criterion of the tested steel doors

\begin{tabular}{|c|c|c|}
\hline Fire test & Failure criterion & $\begin{array}{l}\text { Location of flames appearing on } \\
\text { the unexposed side }\end{array}$ \\
\hline $\begin{array}{l}\text { Steel door opening into } \\
\text { the fire in an insulated } \\
\text { lightweight steel-studs } \\
\text { gypsum-faced wall } \\
\text { (W2D1 HS) }\end{array}$ & $\begin{array}{l}\text { - Insulation failure at } 27 \\
\text { minutes. } \\
\text { - Integrity failure, emergence of } \\
\text { flame at the top corner on the } \\
\text { hinge edge at } 27 \text { minutes. } \\
\text { - Cotton pad failure at } 27 \\
\text { minutes, at mid-height on the } \\
\text { hinge edge. }\end{array}$ & \\
\hline $\begin{array}{l}\text { Steel door opening away } \\
\text { from the fire in an } \\
\text { insulated lightweight } \\
\text { steel-studs gypsum- } \\
\text { faced wall } \\
\text { (W2D1 OHS) }\end{array}$ & $\begin{array}{l}\text { - Integrity failure, cotton pad } \\
\text { test, } 19 \text { minutes, at location } \\
\text { V11. }\end{array}$ & \\
\hline $\begin{array}{l}\text { Steel door opening away } \\
\text { from the fire in non- } \\
\text { insulated light steel- } \\
\text { studs gypsum-faced wall } \\
\text { (W1D1 OHS) }\end{array}$ & $\begin{array}{l}\text { - Integrity failure at } 25 \text { minutes. } \\
\text { - At } 23 \text { minutes flames at } \\
\text { location V11 and Cotton pad } \\
\text { test failure at } 25 \text { minutes. }\end{array}$ & \\
\hline $\begin{array}{l}\text { Steel door opening away } \\
\text { from the fire in a rigid } \\
\text { masonry wall } \\
\text { (W4D1 OHS) }\end{array}$ & $\begin{array}{l}\text { - Integrity failure, flame } \\
\text { emerging at lock-case area at } \\
38 \text { minutes. }\end{array}$ & \\
\hline
\end{tabular}




\section{CONCLUSIONS}

In this paper, the authors presented the experimental measurements of the thermal and mechanical behaviour of steel doors when installed in masonry or lightweight steel-studs plasterboard-faced partition walls during fires. The cavity of the lightweight supporting walls were either filled with Rockwool insulation or left empty. The direction of the fire was either with the door opening into the furnace (hinge side) or with the door opening away from the furnace (opposite hinge side). The full scale fire tests of the doors-walls assemblies were supported by plasterboard and steel doors manufacturers.

The following conclusions can be reached:

1. Only the steel door in the rigid wall achieved the desired fire resistance rating of 30 minutes. Identical steel doors installed in lightweight partition walls had a reduced fire resistance. This is of significant implications for safety issues related to fire rating of steel doors.

2. The integrity criterion of fire resistance duration was found to be 38, 25 and 19 minutes for the same door when installed in masonry wall, uninsulated lightweight wall and insulated light wall respectively.

3. For the insulation criterion of the door-leaf, the direction of the fire with the door opening into the furnace was found to be most onerous. After 30 minutes of exposure to the standard fire test the average unexposed door-leaf side temperature was $115{ }^{\circ} \mathrm{C}$ when the door opened away from the furnace and $146^{\circ} \mathrm{C}$ when the door opened into the furnace. The maximum recorded temperatures on the unexposed side of the door-leaf, after 30 minutes exposure, were $148^{\circ} \mathrm{C}$ and $213^{\circ} \mathrm{C}$ respectively.

4. Providing cavity insulation of the supporting steel-studs plasterboard-faced partition wall resulted in less duration of integrity fire resistance of the door-leaf during exposure to fire 
on the opposite-hinge-side (OHS). It is noteworthy that the European codes of practice, BS EN 1363-1 and BS EN 1634-1, require that such wall cavities not to include insulation. The door in the insulated wall exhibited $25 \%$ less fire resistance duration than that in the wall without insulation.

The experimental data generated during this phase of the project are currently being used by the authors to develop a calibrated and validated numerical tool for predicting the transient and mechanical behaviour of doors and walls assemblies during fires. Such tools will enable engineers to carry out digital simulations of the fire test during the conceptual stage of the product design process. The numerical modelling and analysis of the transient thermomechanical behaviour of doors-walls assemblies will be reported in a subsequent paper.

\section{AKNOWLEDGEMENT}

Thanks are due to the Swiss Federal Laboratories for Material Testing and Research for making this project possible.

\section{REFERENCES}

[1] Bažant, Z., \& Le, J. (2008). What did and did not cause collapse of World Trade Center twin towers in New York? Journal of Engineering Mechanics, 134 No.10, (October 2008), 892907. doi:10.1061/(ASCE00733-9399(2008)134:10(892)

[2] Nassif, A. Y., Yoshitake, I., \& Allam, A. (2014). Full-scale fire testing and numerical modelling of the transient thermo-mechanical behaviour of steel-stud gypsum board partition walls. Construction and Building Materials, 59, 51-61.

doi:10.1016/j.conbuildmat.2014.02.027 
[3] Alfawakhiri, F., Sultan, M. A., and MacKinnon, D. H. (1999). Fire Resistance of Loadbearing Steel-Stud Wall Protected with Gypsum Board: A Review. Fire technology, 35(4), 308-335. Retrieved from http://dx.doi.org/10.1023/A:1015401029995

[4] Sultan, M. (1996). A model for Predicting Heat Transfer Through Noninsulated Steel-Stud Gypsum Board Wall assemblies Exposed to Fire. Fire Technology, Third Quarter 1996.

[5] Sultan, M.A. and Kodur, V.R., (2000). Light-weight frame wall assemblies: Parameters for consideration in fire resistance performance based design. Fire Technology, 36(2), 75-88.

[6] Feng, M., Wang, Y. C., and Davis, J. (2003). Thermal performance of cold-formed thinwalled steel panel systems in fire. Fire Safety Journal, 38(4), 365-394. doi:10.1016/S03797112(02)00090-5

[7] Feng, M. and Wang, Y.C., (2005). An experimental study of loaded full-scale cold-formed thin-walled steel structural panels under fire conditions. Fire Safety Journal, 40(1), 43-63.

[8] Manzello, S. L., Grosshandler, W. L., and Mizukami, T. (2009). Furnace Testing of FullScale Gypsum Steel Stud Non-Load-Bearing Wall Assemblies: Results of Multi-Laboratory Testing in Canada, Japan, and USA. Fire Technology, 46(1), 183-200. doi:10.1007/s10694009-0090-z

[9] Mehaffey, J. R., Cuerrier, P., and Carisse, G. (1994). A Model for Predicting Heat Transfer Through Gypsum Board/Wood-Stud Walls Exposed to Fire. Fire and Materials, 18, 297-305.

[10] Young, S., and Clancy, P. (2001). Structural modelling of light-timber framed walls in fire. Fire Safety Journal, 36(3), 241-268. doi:10.1016/S0379-7112(00)00053-9 
[11] Cooper, L \& Nelson, H (1992). Feeling a door to see if fire is on the other side. Fire Technology, 28(3), 251-256.

[12] Tabaddor, M., Gandhi, P. D., \& Jones, G. (2009). Thermo-mechanical Analysis of Fire Doors Subjected to a Fire Endurance Test. Journal of Fire Protection Engineering, 19(1), 51-71. doi:10.1177/1042391508098899

[13] Capote, J. a., Alvear, D., Abreu, O., Lazaro, M., Boffill, Y., Manzanares, a., \& Maamar, M. (2013). Assessment of Physical Phenomena Associated to Fire Doors During Standard Tests. Fire Technology, 49(2), 357-378. doi:10.1007/s10694-012-0270-0

[14] British Standard, BS EN 1363-1, 1999 “Fire resistance tests -Part1: General requirements”

[15] BS EN 1634-1: 2000 “Fire resistance tests for doors and shutters assemblies- Part 1: Fire doors and shutters

[16] British Standard, BS EN 1991-1-2, (2002) "Eurocode 1: Actions on structures -Part 1-2: General actions — Actions on structures exposed to fire”

[17] Lennon, T, Moore, D.B., Wang, Y.C. and Bailey C.G. (2006) “Designers guide to EN1991-12, EN1992-1-2, EN1993-1-2 and EN1994-1-2”. Thomas Telford Publishing, London, 2006, ISBN 978-0-7277-3157-9. 